\title{
Physician's Perception Versus Patient's Actual Incidence of Drug Non-adherence in Chronic Illnesses
}

\author{
Amber Tahir ${ }^{1}$, Anum S. Siddiqui ${ }^{2}$, Masood Jawaid ${ }^{3}$, Kamran Ali Zaman ${ }^{4}$ \\ 1. Internal Medicine, Dow University of Health Sciences, Karachi, PAK 2. Clinical Research Associate, \\ Clinision, Pharmevo Pvt. Limited 3. Director Medical Affairs, Pharmevo (pvt) Ltd, Jinnah Sindh Medical \\ University, Karachi, PAK 4. Clinical Research Assistant, Pharmevo Pvt. Limited
}

$\square$ Corresponding author: Amber Tahir, siddiquiambertahir@gmail.com Disclosures can be found in Additional Information at the end of the article

\section{Abstract}

\section{Objectives}

Treatment adherence is crucial to the success of a management plan. The objectives of this study are (i) to assess medication adherence in patients with chronic diseases, (ii) to assess if physicians correctly perceive medication adherence among said patients, and (iii) to investigate the factors associated with low drug adherence.

Materials \& methods

This observational cross-sectional study included 283 patients and 208 physicians from various hospitals in Karachi, Pakistan. The participants in the "patient group" completed the eightitem Morisky Medication Adherence Scale form. The participants in the "physician group" completed a questionnaire with questions related to their perception of their patients' characteristics of adherence to medical prescriptions. Data were entered and analyzed using the Statistical Package for Social Sciences (SPSS) for Windows, Version 22.0. (IBM Corp., Armonk, NY).

\section{Results}

The actual incidence of low drug adherence among patients with chronic diseases is $85 \%$. However, the perceived incidence by physicians is $40 \%$. Low adherence was common in women, individuals aged 35 to 50 years, and individuals who were single and illiterate. Adherence decreased with an increasing number of pills, duration of treatment, and increasing average expense of medications. The actual most common barrier to adherence among patients is medication cost; however, physicians perceive forgetfulness to be the more common barrier.

\section{Conclusion}

\section{(C) Copyright 2017}

Tahir et al. This is an open access article distributed under the terms of the Creative Commons Attribution License CC-BY 3.0., which permits unrestricted use, distribution, and reproduction in any medium, provided the original author and source are credited. 
Categories: Family/General Practice, Psychology, Public Health

Keywords: medication adherence, mmas, chronic illnesses, polypharmacy, medication cost, morisky medication adherence scale

\section{Introduction}

The selection of appropriate investigations and treatment regimen forms the basis of disease management in the practice of medicine. However, the role of patient compliance/treatment adherence in the success of a management plan should not be underestimated [1].

The World Health Organization defines compliance as the degree of accuracy to which a patient follows the medical advice of his/her healthcare provider (HCP). Treatment adherence is defined as the degree to which the person's behavior correlates with the agreed upon recommendations from his/her HCP. Both the terms are interrelated; however, "compliance” suggests the patient is passively abiding by the orders of the physician, while "adherence" highlights how the patient is also a part of the management plan, making it the preferred term $[2]$.

Even when used as interchangeable terms, their implications remain different. Steiner and Earnest [3] have rightly stated these terms “exaggerate the physician's control over the process of taking medications." No single term can successfully encompass the wholesome phenomenon of abiding by physician recommendations for chronic illness sufferers.

Meanwhile, some writers have segregated adherence as primary and secondary. Primary nonadherence is the failure of initiation of medical therapy, while secondary non-adherence is the failure of adequately abiding by the medical therapy once initiated [4].

Although treatment adherence is a wider terminology that encompasses both pharmacological and nonpharmacological recommendations of HCPs, for this study, only drug adherence was taken into consideration-a key factor associated with the success of pharmacological therapy. Patients are drug adherent when they take their prescribed medications at given dosages and timings as recommended by their HCPs [5]. Non-adherence to medications is a widely recognized phenomenon and has presented as a major public health concern which significantly contributes to morbidity, mortality, and healthcare costs [6]. Adherence or nonadherence to medications is governed by factors falling into five categories: socioeconomic factors, therapy-related factors, patient-related factors, condition-related factors, and health system/healthcare team-related factors [2].

Identifying medication adherence-related behaviors among patients with chronic illnesses is the foremost step towards obtaining adequate evidence on the consequences, predictors/risk factors, and strategies to improve medication adherence. For this purpose, numerous direct and indirect tools have been proposed. Adherence assessing tools can be subjective (e.g., selfreported by the patient or caregivers) or objective (e.g., counting pills, examining pharmacy refill records, using electronic medication event monitoring systems, or biochemical in which serum or urine drug levels are measured).

An accurate measurement of medication adherence can be quite challenging with its parameters carefully delineated and appropriated for customized situations. The selected tool must be valid, consistent, reliable, and sensitive to change. Hence, there remains no single gold standard tool to measure medication adherence, which itself is a barrier to treatment adherence research [7]. The choice of a tool depends on the individual attributes and goals of the study, the extent of resources available for the study, the clinical setting, the patient's acceptance, and the convenience of the method. Research suggests medication non-adherence must be taken as a diagnosable and treatable medical condition, and for its diagnosis, a 
patient-centered approach remains the most accomplished one [8].

Hence, to assess patient adherence to physician-prescribed medication in this study, an adherence-specific self-report questionnaire from the literature, the Morisky Medication Adherence Scale (MMAS), was used [9]. Physicians' perceptions of drug adherence among their patients were also compared to the patients' actual drug adherence, which is a lesser studied phenomenon.

\section{Materials And Methods}

In this observational cross-sectional study, 283 patients and 208 physicians participated from various public and private hospitals of Karachi, Pakistan after providing informed consent.

The participants included in the "patient group" were $\geqslant 20$ years old and suffered from chronic illnesses, such as diabetes mellitus (DM), hypertension (HTN), ischemic heart disease (IHD) (diagnosed for more than five years), or a chronic physiological condition, such as pregnancy. The participants in the "patient group" completed a questionnaire which included their sociodemographic data, clinical characteristics of their diseases, and the characteristics of their medical prescription. This group also completed the eight-item MMAS, a simple and reliable tool to identify the behavior of patients associated with adherence to prescribed medications.

The MMAS was originally administered in patients with HTN; where the results were reliable ( $\alpha$ $=0.83$ ), a significant correlation was seen with blood pressure control $(\mathrm{P}<0.05)$, and the tool proved to be $93 \%$ sensitive in detecting patients with poor blood pressure control [10]. Response choices were No/Yes for the first seven items and a five-point Likert response scale for the eighth item. The response "No" was given one point while a "Yes" response was given zero points, except for the fifth item where a "No" response was given a score of zero while a "Yes" response was given a score of one point. For the eighth item, if the participant chose response "A," the score was one point, and if they chose response "E" the score was zero points.

Responses “B, C, and D" were scored " $0.25,0.50$, and 0.75 ", respectively. The total score on the MMAS- 8 can range from 0 to 8 , with scores of $<6,6$ to $<8$, and 8 reflecting low, medium, and high adherence, respectively.

The participants in the "physician group" completed a questionnaire which included questions related to their perception of their patients' characteristics of adherence to medical prescription. Data were entered and analyzed using IBM SPSS Statistics for Windows, version 22.0. (IBM Corp., Armonk, NY). MMAS responses were analyzed and compared with patient sociodemographic and clinical characteristics. Physicians' perceptions of patient medication adherence patterns and barriers to adherence were assessed and compared to the actual pattern of patient medication adherence to deduce if the physicians were accurately aware of the behavior of their patients.

\section{Results}

Of the 283 patients in the study, $37.8 \%(n=107)$ were men and $62.2 \%(n=176)$ were women. Their mean age was 37 years with an age range of 20 to 76 years. Low drug adherence was reported by $84.8 \%$ of the sample, $12.4 \%$ had medium adherence, and $2.8 \%$ showed high drug adherence according to the MMAS assessment. The sociodemographic characteristics of these patients, as compared with their MMAS score, showed that most low drug adherent patients were women, aged 20 to 35 years, married, and attending a university (Table 1). 


\section{Cureus}

\begin{tabular}{|c|c|c|c|}
\hline $\begin{array}{l}\text { PATIENT CHARACTERISTICS n } \\
=283(100 \%)\end{array}$ & $\begin{array}{l}\text { LOW ADHERENCE } \mathrm{n}= \\
240(84.8 \%)\end{array}$ & $\begin{array}{l}\text { MEDIUM ADHERENCE } \mathrm{n}= \\
35(12.4 \%)\end{array}$ & $\begin{array}{l}\text { HIGH ADHERENCE } \mathrm{n}= \\
8(2.8 \%)\end{array}$ \\
\hline GENDER & $\mathrm{n}(\%)$ & $\mathrm{n}(\%)$ & $\mathrm{n}(\%)$ \\
\hline Male & $89(83.2 \%)$ & $14(13.1 \%)$ & $4(3.7 \%)$ \\
\hline Female & 151 (85.8\%) & $21(11.9 \%)$ & $4(2.3 \%)$ \\
\hline \multicolumn{4}{|l|}{ AGE } \\
\hline 20-35 years & $120(84.5 \%)$ & $20(14.1 \%)$ & $2(1.4 \%)$ \\
\hline $35-50$ years & $66(85.7 \%)$ & $9(11.7 \%)$ & $2(2.6 \%)$ \\
\hline 51-65 years & $41(85.4 \%)$ & $4(8.3 \%)$ & $3(6.3 \%)$ \\
\hline$>65$ years & $13(81.3 \%)$ & $2(12.5 \%)$ & $1(6.2 \%)$ \\
\hline \multicolumn{4}{|l|}{ MARITAL STATUS } \\
\hline Single & $63(88.7 \%)$ & $8(11.3 \%)$ & $0(0 \%)$ \\
\hline Married & $163(82.7 \%)$ & $26(13.2 \%)$ & $8(4.1 \%)$ \\
\hline Divorced & $6(85.7 \%)$ & $1(14.3 \%)$ & $0(0 \%)$ \\
\hline Widow & $8(100 \%)$ & $0(0 \%)$ & $0(0 \%)$ \\
\hline \multicolumn{4}{|l|}{ EDUCATION } \\
\hline Nil & $7(87.5 \%)$ & $1(12.5 \%)$ & $0(0 \%)$ \\
\hline Primary & $38(84.4 \%)$ & $5(11.2 \%)$ & $2(4.4 \%)$ \\
\hline Secondary & $61(82.4 \%)$ & $10(13.5 \%)$ & $3(4.1 \%)$ \\
\hline University & $134(85.9 \%)$ & $19(12.2 \%)$ & $3(1.9 \%)$ \\
\hline
\end{tabular}

TABLE 1: Patient Baseline Characteristics and Associated Drug Adherence According to the Morisky Medication Adherence Scale (MMAS)

The clinical characteristics of these patients, according to their MMAS score showed that $80 \%$ to $88 \%$ of people with diabetes, hypertension, and pregnant women were low drug adherent, while almost $95 \%$ of people with IHD were low drug adherents. Individuals taking more than five medications per day, being treated for two to five years, spending 5,000 Rupees (Rs) to 10,000 Rs monthly on medicines, and those who buy their medicines from private pharmacies were most prone to low drug adherence (Table 2).

\begin{tabular}{|c|c|c|c|}
\hline $\begin{array}{l}\text { PATIENT CHARACTERISTICS } n= \\
283(100 \%)\end{array}$ & $\begin{array}{l}\text { LOW ADHERENCE } n= \\
240(84.8 \%)\end{array}$ & $\begin{array}{l}\text { MEDIUM ADHERENCE } n= \\
35(12.4 \%)\end{array}$ & $\begin{array}{l}\text { HIGH ADHERENCE } n \\
=8(2.8 \%)\end{array}$ \\
\hline & n (\%) & n (\%) & n (\%) \\
\hline
\end{tabular}




\section{Cureus}

\section{ASSOCIATED MEDICAL \\ CONDITIONS}

Diabetes mellitus

Hypertension

Ischemic heart disease

Pregnancy

Others

HOSPITALIZED IN THE LAST 6

MONTHS

NUMBER OF MEDICATIONS PER

DAY

1

$2-3$

4-5

$>5$

DURATION OF TREATMENT IN YEARS

$<1$

$1-2$

3-5

$>5$

MONTHLY MEDICATION

EXPENSE IN RUPEES

$<1000$

$1,000-5,000$

$5,001-10,000$

$>10,000$

SOURCE OF MEDICATION

Supplied from public hospital pharmacy

Bought from a private pharmacy

Bought by a family member
$39(88.6 \%)$

$5(11.4 \%)$

$0(0 \%)$

$39(81.3 \%)$

$18(94.7 \%)$

$81(84.4 \%)$

$63(82.9 \%)$

$53(86.9 \%)$

$5(10.4 \%)$

$4(8.3 \%)$

$1(5.3 \%)$

$0(0 \%)$

$14(14.6 \%)$

$1(1.0 \%)$

$10(13.2 \%)$

$3(3.9 \%)$

$7(11.5 \%)$

$1(1.6 \%)$

$10(13.3 \%)$

$3(4.0 \%)$

$17(11.9 \%)$

$3(2.1 \%)$

$43(82.7 \%)$

$7(13.5 \%)$

$2(3.8 \%)$

$12(92.3 \%)$

$1(7.7 \%)$

$0(0 \%)$

$112(83.0 \%)$

$20(14.8 \%)$

$3(2.2 \%)$

$10(13.7 \%)$

$1(1.4 \%)$

$3(5.1 \%)$

$3(5.1 \%)$

$2(13.3 \%)$

$1(6.7 \%)$
$28(77.8 \%)$

$140(83.8 \%)$

$63(91.3 \%)$

$9(81.8 \%)$

$13(76.5 \%)$

$168(88.0 \%)$

$59(78.7 \%)$
$7(19.4 \%)$

$1(2.8 \%)$

$21(12.6 \%)$

$6(3.6 \%)$

$5(7.3 \%)$

$1(1.4 \%)$

$2(18.2 \%)$

$0(0 \%)$

$4(23.5 \%)$

$0(0 \%)$

$21(11.0 \%)$

$2(1.0 \%)$

$10(13.3 \%)$

$6(8.0 \%)$ 


\section{Cureus}

\section{TABLE 2: Patient Clinical Characteristics and Associated Drug Adherence According to the Morisky Medication Adherence Scale (MMAS)}

This study included 208 medical practitioners who practiced general medicine, general surgery, cardiology, and gynecology and obstetrics. When inquired about the drug adherence rate among their patients, they perceived only $39 \%$ of their patients were low drug adherent as compared to the actual $85 \%$. Our study observed a substantial difference in physicians' knowledge of patient drug adherence, patient medication preferences, and patient barriers to adequate drug adherence. A comparison of the views of these two study groups is shown in Table 3.

PHYSICIANS' PERCEPTION OF PATIENT'S DRUG

PREFERENCES \& ADHERENCE $n=208(100 \%)$

LOW ADHERENCE TO MEDICATIONS

$39.86 \%$

AVERAGE DAILY COST (Mean \pm SD in Pakistani Rupees)

$345.14( \pm 261.15)$

COMMONLY MISSED DRUG DOSE

Midday (52.9\%)

Morning (31.2\%)

Night (15.9\%)

PREFERRED MEDICATION TYPE

Rapid-acting drugs (88.9\%)

Delayed action drugs (11.1\%)

PREFERRED DAILY MEDICATION DOSE

Once daily (87\%)

More than one dose per day (13\%)

PREFERRED MEDICATION FORM

Fixed dose combination (77.3\%)

Multiple tablets per dose $(22.7 \%)$
PATIENTS' ACTUAL DRUG PREFERENCES \&

ADHERENCE $\mathrm{n}=\mathbf{2 8 3}(\mathbf{1 0 0 \%})$

$84.8 \%$

$3,359.5( \pm 2,881.00)$

Morning (45.2\%)

Midday (39.6\%)

Night (15.2\%)

Rapid-acting drugs (80.5\%)

Delayed action drugs (19.5\%)

Once daily $(74.9 \%)$

More than one dose per day $(25.1 \%)$

Fixed dose combination (58.7\%)

Multiple tablets per dose $(41.3 \%)$

TABLE 3: Comparison of Physician's Perception and Patient's Actual Pattern of Drug Preferences and Adherence 


\section{Cureus}

As seen in Table 4, physicians undermined the common barriers decreasing drug adherence among their patients over time. The most common barrier from both physician's and patient's point of view was forgetfulness; however, the youngest age group most commonly forgot to take its medicines. From a patient's point of view, these barriers were more worrisome, common, and their presence made a patient more prone to low drug adherence (Table 4 ).

\begin{tabular}{|c|c|c|}
\hline ADHERENCE & $\begin{array}{l}\text { PHYSICIAN'S PERCEPIION n = } 208 \\
(100 \%)\end{array}$ & $\begin{array}{l}\text { PATIENT'S ACTUAL BARRIERS } \mathrm{n}=283 \\
(100 \%)\end{array}$ \\
\hline Forgetfulness & $41.8 \%$ & $59.3 \%$ \\
\hline Alleviated disease severity & $22.1 \%$ & $36.4 \%$ \\
\hline Medication cost & $29.5 \%$ & $84.9 \%$ \\
\hline Medication taste & $29.6 \%$ & $66.2 \%$ \\
\hline Medication side effects & $36.8 \%$ & $83.6 \%$ \\
\hline Medication unavailability & $25.6 \%$ & $25.3 \%$ \\
\hline Complex medicatıon regımen & $12.5 \%$ & $10.9 \%$ \\
\hline
\end{tabular}

TABLE 4: Comparison of Physician's Perception and Patient's Actual Barriers to Drug Adherence

\section{Discussion}

This study suggests an $85 \%$ incidence of low drug adherence among patients with chronic diseases, which is perceived to be $40 \%$ by their physicians. Low adherence was common in women (85.8\%), individuals aged 35 years to 50 years (85.7\%), individuals who were single (88.7\%), and individuals who were illiterate (87.5\%). Adherence showed a decreasing trend with an increasing number of pills, duration of treatment, and an increasing average expense of medications. The most common barrier to adherence among patients is medication cost; however, physicians perceived forgetfulness to be the more common barrier, which was not related to increasing age of the population. Even then, physicians undermined the average medication expense of their patients by 10 times.

Our study adopted a dual approach-patient-centered as well as physician-centered. This study is among the few studies that compare patients' levels of medication adherence to what is perceived by their physicians. It also includes patients with various chronic diseases and chronic physiological conditions (e.g., pregnancy) as compared to many other studies that only assessed medication adherence among patients with HTN [5, 10-12]. However, our study was limited in that we could have involved a larger sample of patients and could have adopted a more precise adherence assessment method, such as counting pills.

Other studies have reported adherence levels at 52\% [13] and 65\% [14]. However, local data conducted with patients with Type II DM indicate low drug adherence in about $62 \%$ cases and were attributed to polypharmacy [15]. Even our study group did not support or prefer polypharmacy. However, another local study among patients with HTN showed a high adherence rate (77\%) with improved adherence associated with better awareness and 
increasing the number of pills prescribed [16]. Nonetheless, our findings are consistent with other studies where the increasing number of pills has shown a decreasing trend in medication adherence [17].

This study compared physicians' perceptions of patient preferences and barriers to medication adherence, and we found some notable discrepancies. Though other studies report

forgetfulness and side effects to be the more common barriers to drug adherence [18-19] (which aligned with our physician group's perception), the more common adherence barrier in our population was medication expenses. It is impossible for our physicians to correctly estimate the burden of medication expenses on our patients as they highly undermine the cost of their prescribed drugs. The literature also identifies the existence of inconsistent estimation of drug cost by the physicians [20]. Although both our patients and physicians preferred rapid-acting drugs in the form of once-daily dosing and fixed-dose combinations, we could find no substantial studies with which to compare our results.

We recommend more studies with a larger sample and standardized instruments to assess the incongruities among physician perception and patient choices of drug dosages, regimens, and barriers to adherence in order for the physicians to accurately understand the reasons behind such low medication adherence levels. Once the physicians understand these barriers, they can bring about alterations necessary to help make their patients adhere to the medical management of chronic diseases.

\section{Conclusions}

Patients with chronic illnesses have low medication adherence levels. Physicians, however, misinterpret the frequency of low adherence and underestimate the role of medication cost, polypharmacy, and treatment regimen in reduced adherence to medications. These findings should help physicians have a more accurate understanding of the challenges their patients face in long-term adherence to treatment regimens. This understanding may ultimately lead to improved treatment adherence and quality of management once patients' actual challenges are addressed.

\section{Additional Information \\ Disclosures}

Human subjects: Consent was obtained by all participants in this study. Animal subjects: All authors have confirmed that this study did not involve animal subjects or tissue. Conflicts of interest: In compliance with the ICMJE uniform disclosure form, all authors declare the following: Payment/services info: All authors have declared that no financial support was received from any organization for the submitted work. Financial relationships: Anum S. Siddiqui; Masood Jawaid; Kamran Zaman declare(s) a grant and employment from PharmEvo (Pvt) Ltd. These authors are employees of PharmEvo (Pvt) Ltd. However, they have not received any separate honorarium for this research work, nor is this study reporting results of any product. PharmEvo (Pvt) Ltd with its "Clinision" Division provided financial support for administrative work (printing, data collection, statistical analysis, and editing service payment) of the study. . Other relationships: All authors have declared that there are no other relationships or activities that could appear to have influenced the submitted work.

\section{Acknowledgements}

This study is funded by Academic and Research Grant of PharmEvo (Pvt), Ltd.

\section{References}


1. Hamdidouche I, Jullien V, Boutouyrie P, et al.: Drug adherence in hypertension: from methodological issues to cardiovascular outcomes. J Hypertens. 2017, 35:1133-44. 10.1097/HJH.0000000000001299

2. Adherence to long-term therapies: evidence for action. (2003). Accessed: September 29, 2017 : http://apps.who.int/iris/bitstream/10665/42682/1/9241545992.pdf.

3. Steiner JF, Earnest MA: The language of medication-taking. Ann Intern Med. 2000, 132:92630. 10.7326/0003-4819-132-11-200006060-00026

4. Lam WY, Fresco P: Medication adherence measures: an overview . BioMed Res Int. 2015, 2015:217047. 10.1155/2015/217047

5. Moharamzad Y, Saadat H, Shahraki BN, et al.: Validation of the Persian version of the 8-item Morisky Medication Adherence Scale (MMAS-8) in Iranian hypertensive patients. Global J Health Sci. 2015, 7:173-83. 10.5539/gjhs.v7n4p173

6. Brown MT, Bussell JK: Medication adherence: WHO cares?. Mayo Clin Proc. 2011, 86:304-14. 10.4065/mcp.2010.0575

7. Vermeire E, Hearnshaw H, Van Royen P, Denekens J: Patient adherence to treatment: three decades of research. A comprehensive review. J Clin Pharm Ther. 2001, 26:331-42. 10.1046/j.1365-2710.2001.00363.x

8. Marcum ZA, Sevick MA, Handler SM: Medication nonadherence: a diagnosable and treatable medical condition. JAMA. 2013, 309:2105-106. 10.1001/jama.2013.4638

9. Morisky DE, DiMatteo MR: Improving the measurement of self-reported medication nonadherence: response to authors. J Clin Epidemiol. 2011, 64:255-57.

10.1016/j.jclinepi.2010.09.002

10. Morisky DE, Ang A, Krousel-Wood M, Ward HJ: Predictive validity of a medication adherence measure in an outpatient setting. J Clin Hypertens (Greenwich). 2008, 10:348-54. 10.1111/j.1751-7176.2008.07572.x

11. Hacıhasanoğlu Aşılar R, Gözüm S, Çapık C, Morisky DE: Reliability and validity of the Turkish form of the eight-item Morisky medication adherence scale in hypertensive patients. Anadolu Kardiyol Derg (Anatol J Cardiol). 2014, 14:692-700. 10.5152/akd.2014.4982

12. Saleem F, Hassali MA, Akmal S, et al.: Translation and validation study of Morisky Medication Adherence Scale (MMAS): the Urdu version for facilitating person-centered healthcare in Pakistan. Int J Pers Cent Med. 2012, 2:384-90.

13. Krousel-Wood M, Joyce C, Holt E, et al.: Predictors of decline in medication adherence: results from the cohort study of medication adherence among older adults. Hypertension. 2011, 58:804-10. 10.1161/HYPERTENSIONAHA.111.176859

14. Lee GK, Wang HH, Liu KQ, et al.: Determinants of medication adherence to antihypertensive medications among a Chinese population using Morisky Medication Adherence Scale. PLoS One. 2013, 8:e62775. 10.1371/journal.pone.0062775

15. Shams N, Amjad S, Kumar N, et al.: Drug non-adherence in type 2 diabetes mellitus; predictors and associations. J Ayub Med Coll Abbottabad. 2016, 28:302-307.

16. Hashmi SK, Afridi MB, Abbas K, et al.: Factors associated with adherence to anti-hypertensive treatment in Pakistan. PLoS One. 2007, 2:e280. 10.1371/journal.pone.0000280

17. Pasina L, Brucato AL, Falcone C, et al.: Medication non-adherence among elderly patients newly discharged and receiving polypharmacy. Drugs Aging. 2014, 31:283-89.

10.1007/s40266-014-0163-7

18. Khan MU, Shah S, Hameed T: Barriers to and determinants of medication adherence among hypertensive patients attended National Health Service Hospital, Sunderland. J Pharm Bioallied Sci. 2014, 6:104-108. 10.4103/0975-7406.129175

19. Nair KV, Belletti DA, Doyle JJ, et al.: Understanding barriers to medication adherence in the hypertensive population by evaluating responses to a telephone survey. Patient Prefer Adherence. 2011, 5:195-206. 10.2147/PPA.S18481

20. Schutte T, Tichelaar J, Nanayakkara P, et al.: Students and doctors are unaware of the cost of drugs they frequently prescribe. Basic Clin Pharmacol Toxicol. 2017, 120:278-83.

10.1111/bcpt.12678 